\title{
Aplikasi Mendatang Sistem Informasi Sumber Daya Manusia Perguruan Tinggi X di Pagar Alam
}

\author{
Buhori Muslim ${ }^{1}$ \\ ${ }^{1}$ Program Studi Informatika, Sekolah Tinggi Teknologi Pagar Alam \\ 1buhori45@yahoo.com
}

\begin{abstract}
Abstrak- PT X memiliki rencana strategis, Adapun yang dilakukan yakni membuat rancangan strategis Sistem Informasi di PT X, dengan fokus perhatian pada bagian Sumber daya manusia (SDM) menggunakan pendekatan rantai nilai (value chain) Penelitian dilakukan dengan tujuan Membuat perencanaan strategis sistem informasi (SI) sumber daya manusia PT $X$ untuk menciptakan keunggulan bersaing dalam mewujudkan visi, misi dan tujuan organisasi, Dengan adanya penelitian ini akan memudahkan dalam pengelolaan Sumber Daya Manusia pada PT X untuk meningkatkan keunggulan kompetitifnya dengan menggunakan perencanaan strategis system informasi Sumber Daya Manusia.
\end{abstract}

Kata Kunci-Rencana strategis, sistem informasi, Manusia, value chain, FiveForce Porter, McFarlan.

\section{Pendahuluan}

Perguruan Tinggi (PT) X adalah sebuah PT memiliki beberapa Prodi. Sistem informasi (SI) merupakan daya saing dalam meningkatkan kualitas SDM. Perencanaan strategis SI jadi kunci sebelum menerapkan SI \& teknologi informasi (TI) di PT. Perencanaan strategis yang tepat mendukung rencana \& pengembangan SDM. Perencanaan strategis SI SDM pada PT saat meningkatan daya saing dibutuhkan saat menjalankan aktivitas menghadapi perubahan lingkungan eksternal \& internal, mempengaruhi hidup organisasi [1].

Melalui analisis lingkungan baik eksternal maupun internal, diperoleh suatu penilaian mengenai pengaruh faktor- faktor tersebut dalam memberikan peluang dan ancaman atau kekuatan dan kelemahan, terhadap pengelolaan SDM, sehingga PT bisa mengoptimalkan kekuatan, peluang \& mengantisipasi ancaman atau memperbaiki kelemahan. Bentuk perencanaan strategis SI SDM dianalisa menggunakan metode analisis Value Chain untuk analisa lingkungan bisnis internal, Five Forces Model untuk analisa lingkungan bisnis eksternal dan McFarlan Strategic Grid untuk analisa kondisi SI/TI internal saat ini.

Berdasarkan analisis di simpulan PT direkomendasikan menerapkan strategi SDM. Masalahnya bagaimana membuat rencana strategis SI SDM untuk menciptakan keunggulan bersaing dalam mewujudkan visi, misi dan tujuan organisasi. Maka masalah dibatasi membahas perencanaan strategis SDM untuk proses bisnis terkait Tri Dharma, Hasil penelitian blue print rencana strategis SDM, rencana strategis dibuat dan dikembangkan dari SI SDM yang ada saat penelitian dilakukan agar sesuai dengan arah perkembangan organisasi, Metode analisisnya value chain, Analisis lingkungan eksternal dengan Five force factors Porter.

Tujuan penelitian membuat rencana strategis SI SDM PT X $\&$ manfaat penelitian memberikan referensi yang memperkaya pengetahuan bidang perencanaan strategis SDM, Memberikan panduan terhadap rencan strategis SDM PT X untuk keunggulan bersaing dengan organisasi sejenis dan mewujudkan visi, misi institusi. Peneliti menerapkan metode action research dimana peneliti terlibat secara langsung proses pengambilan data hingga analisis \& kesimpulan, lebih dahulu membuat rancangan strategis SI, fokus perhatian di bagian Inbound Logistic dan Operasional memanfaatkan pendekatan value chain. Caranya dengan mengumpulan data, data diperoleh dengan wawancara Pimpinan, Ketua Biro Administrasi Umum dan Kepegawaian. Bahan wawancara adalah Apakah proses penerimaan SDM di PT sesuai standar.

Studi literatur menelusuri referensi atau literatur terkait perencanaan strategi SI PT sesuai standar Kementrian Ristekdikti. Beberapa dibahas tinjauan pustaka. Metode Analisis Data, data yang di dapatkan seperti SOP, dianalisis dengan identifikasi aktifitas, biaya diperlukan \& mengembangkan keunggulan.

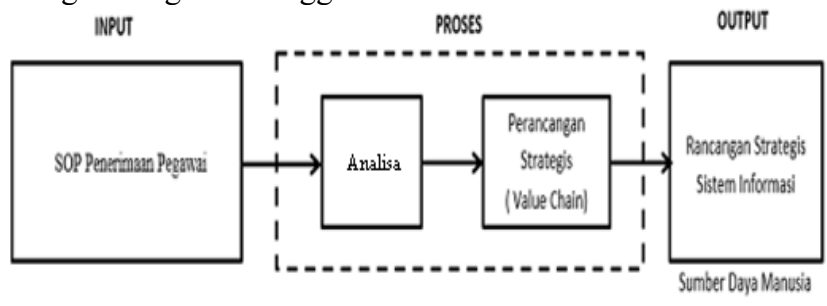

Gambar 1. Blok Diagram Penelitian

\section{KAJIAN PUSTAKA}

Bagian ini membahas tentang teori dan renstra SI penelitian sebelumnya dilaksanakan dengan metode Ward \& Pappard. Seperti penelitian rencana Strategi SI Retail pada PT. Retail X, banyak organisasi melakukan pengembangan TI hanya berdasarkan apa yang dipercayai atau rekomendasi vendor. Pada hal Pengembangan SI/TI perlu rencana matang dan menyesuaikan dengan tujuan strategis bisnis untuk menghindari kerugian lebih besar sisi finansial \& investasi.

Pengembangan SI \& TI tak sistematis terkesan tambal sulam, memenuhi kebutuhan sesaat, tidak ada skala prioritas [1] dan tak sesuai dengan proses bisnis berjalan memiliki keunikan tersendiri. PT.Retail X perusahaan retail baru. Untuk menjaga daya saing dengan perusahaan sejenis baik lokal dan internasional Perusahaan harus menyusun rencana SI untuk mendukung kegiatan usaha, rencana strategis SI merupakan pendekatan sistematis tentang apa yang dianggap efektif dan efisien memenuhi kebutuhan informasi. Pendekatan rencana strategis SI [6] mendasari penelitian ini dan memanfaatkan beberapa metode analisis lain: Five Force Model, Analisis Swot, Balance Score Card, Mcfarlan Grid. Hasilnya adalah 
Cetak Biru rencana strategis yang mengacu pada rencana bisnis organisasi berdasarkan data yang diperoleh melalui metode analisis yang digunakan serta melibatkan seluruh komponen organisasi [3]. Berikutnya rencana Strategi SI institusi pendidikan diteliti [5], rencana Strategis SI institusi pendidikan tinggi studi kasus sekolah tinggi ilmu komunikasi dan sekretaris tarakanita, ini tarakanita merupakan lembaga pendidikan berdiri 1968. Selama 41 tahun menghasilkan banyak sekretaris profesional dibidangnya. Belakang dirasa ada beberapa masalah seperti rumusan strategi bisnis yang kurang didukung analisis data handal. Pelayanan terhadap pelanggan, kurang optimal penggunaan sumber daya serta jumlah lulusan makin menurun, akibatnya aktivitas lembaga semakin bertambah, maka permasalahan perlu dibenahi secepatnya agar sasaran bisnis dapat tercapai.

\section{Metode PenElitian}

Membahas teori dan metode yang di pergunakan pada penelitian yang dilakukan:

\section{A. Sistem Informasi SDM}

SI SDM memberi informasi seluruh pimpinan berkaitan SDM PT. SI SDM unit organisasi terdiri personel pengolah data SDM menggunakan komputer dan non komputer. SI SDM ini program aplikasi komputer berisi program (sistem) tentang manajemen SDM membantu kelancaran PT untuk mencapai tujuan. SI SDM wahana pengumpul, peringkas \& penganalisa data berhubungan erat dengan SDM. Sumber Daya bertalian dengan fungsi SDM sangat banyak. Misal, penilaian SDM melibatkan penyimpanan catatan pegawai di seluruh bagian. SI SDM sebuah aplikasi data base Client Server ada pun data diolah: Biografi, Pendidikan, Keluarga, Pekerjaan, Cuti, Keahlian, Bahasa, Bakat, Minat, Nilai Diklat, Kursus, Mutasi, jabatan, Pangkat, Masa pensiun \& lain-lain.

\section{B. Metodologi Perencanaan Strategi SI}

Pendekatan metodologi versi Ward and Peppard [1] menganalisis dari kondisi investasi SI/TI masa lalu kurang bermanfaat bagi tujuan bisnis organisasi dan menangkap peluang bisnis serta fenomena meningkatkan keunggulan kompetitif PT, bisa memanfaatkan SI \& TI secara optimal. Kurang manfaat investasi SI/TI organisasi karena rencana strategis SI/TI terlalu fokus ke teknologi [1], bukan berdasar kebutuhan bisnis. Metodologi ini terdiri tahapan masukan \& keluaran [6]. Tahap masukan terdiri:

1) Analisis lingkungan bisnis internal, mencakup aspek strategi bisnis saat ini, sasaran, sumber daya, proses serta budaya nilai bisnis organisasi.

2) Analisis lingkungan bisnis eksternal, mencakup aspek ekonomi, industri dan iklim bersaing PT.

3) Analisis lingkungan SI/TI internal, mencakup kondisi SI/TI dari perspektif bisnis, bagaimana kematangan /maturity, kontribusi terhadap bisnis, keterampilan SDM, sumber daya dan infrastruktur teknologi, termasuk portofolio SI/TI.
4) Analisis lingkungan SI \& TI eksternal, mencakup trend teknologi \& peluang pemanfaatannya, serta penggunaan SI/TI oleh kompetitor, pelanggan \& pemasok.

\section{Metode Analisis Renstra SI}

\section{1) Value Chain}

Alat untuk memahami rantai nilai pembentuk produk [2]. Jogiyanto [7] membagi aktivitas bisnis jadi 9, dikelompokan jadi 2 aktivitas besar, yaitu 4 aktivitas pendukung dan 5 aktivitas utama, seperti gambar 2 .

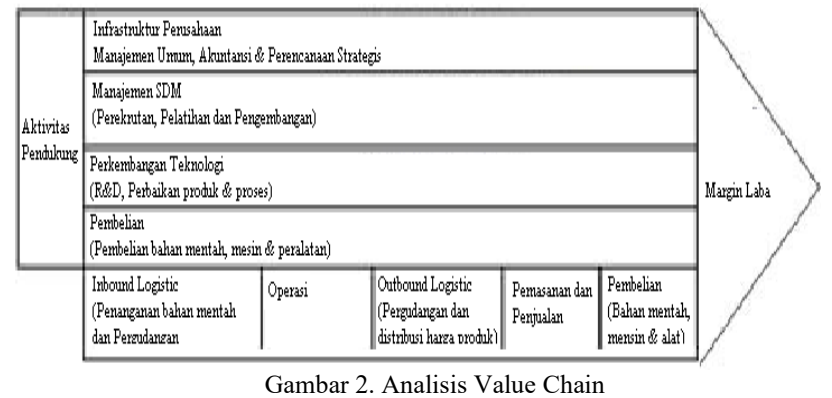

aktivitas pendukung: infrastruktur perusahaan (management and administrative services: manajemen, akuntansi, keuangan \& sebagainya), manajemen SDM (human resource manajement: penerimaan, pelatihan dan pengembangan SDM), pengembangan teknologi (technology development: R\&D, peningkatan kualitas produk \& proses) dan pengadaan barang (procurement). Porter mengidentifikasi 5 kegiatan utama yang biasa terjadi ditiap bisnis: (1) inbound logistics bahan mentah; (2) operasi; (3) outbound logistics barang jadi; (4) pemasaran dan penjualan, (5) layanan konsumen [8]. Porter menjelaskan bahwa untuk mencapai keuntungan kompetisi, 9 kegiatan itu harus terus ditingkatkan nilainya yaitu harus efisien dan efektif. Nilai di tiap kegiatan dibawa kegiatan lainnya dan menambah nilai kegiatan berikutnya, sehingga akhir dari seluruh kegiatan memiliki nilai [4].

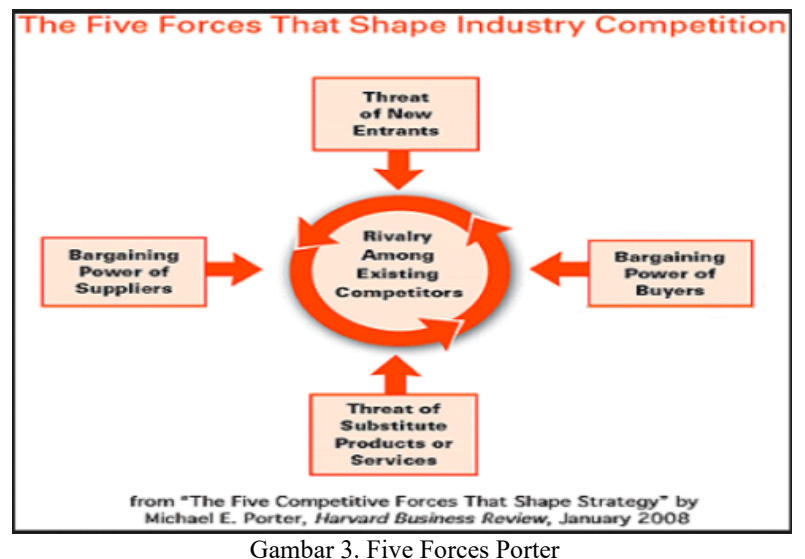


2) Analisis Kompetitif Porter

Dikemukan Michael E. Porter, Five Forces Model Porter adalah strategi bisnis untuk melakukan analisis struktur industri. Analisis didasarkan 5 kekuatan, yaitu: Masuknya Kompetitor, Ancaman Produk/Jasa pengganti, Daya tawar pembeli, Daya tawar supplier dan Persaingan di antara pemain.

\section{3) Strategic Grid Mc-Farlan}

McFarlan analisis aplikasi atau SI operasional Organisasi berdasarkan kondisi saat ini, kondisi yang direncanakan serta aplikasi dianggap berpotensi menunjang bisnis. Pemetaan dibagi atas kategori:

Kuadran 1 merupakan kuadran Support.

Kuadran 2 merupakan kuadran Operational.

Kuadran 3 merupakan kuadran High Potential.

Kuadran 4 merupakan kuadran Strategic.

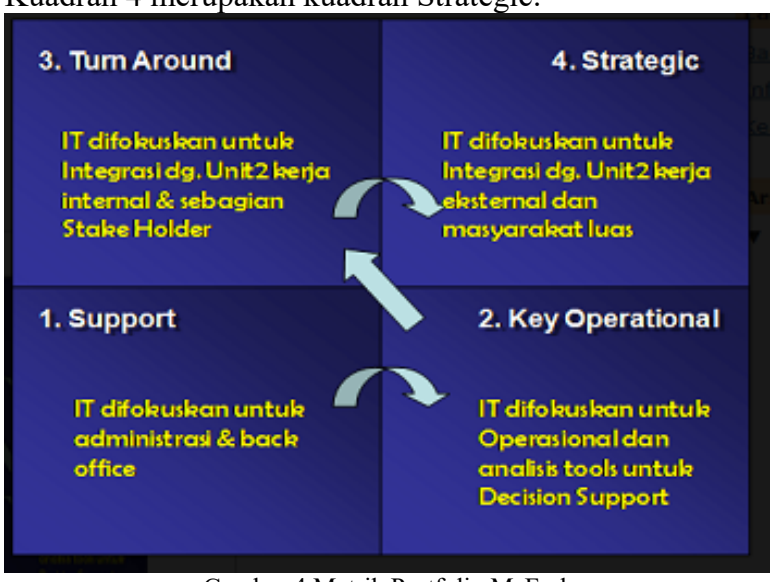

Gambar 4 Matrik Portfolio McFarlan

Pemetaan ini mempermudah manajemen mengambil keputusan menentukan posisi sistem TI Organisasi dalam kuadran itu \& keinginan operasional Organisasi dalam menentukan ke arah mana SI dipenuhi tentu disesuaikan kapabilitas, visi \& misi operasional Organisasi masa mendatang.

\section{HASIL DAN PEMBAHASAN}

Menganalisis langkah yang dilakukan sesuai metodologi dan pengumpulan data yang di rencanakan sampai hasilnya.

\section{A. Modul aplikasi Pengelolaan SDM.}

TABEL 1

FITUR APLIKASI

\begin{tabular}{|l|l|}
\hline \multicolumn{1}{|c|}{ Aplilasi SI } & \multicolumn{1}{c|}{ Keterangan (Fitur) } \\
\hline SI Penelitian SDM & Data Proyek penelitian \\
\hline SI Perenc. SDM & $\begin{array}{l}\text { Rencana keb. SDM Jangka pendek dan } \\
\text { jangka panjang. }\end{array}$ \\
\hline SI Data SDM & Data pegawai dan non pegawai \\
\hline
\end{tabular}

\begin{tabular}{|c|c|}
\hline SI Intelijen SDM & $\begin{array}{l}\text { 1. Data intelijen pemasok } \\
\text { 2. Data intelijen pemerintah } \\
\text { 3. intelijen serikat pekerja } \\
\text { 4. Intelijen masyarakat keuangan. } \\
\text { 5. Intelijen pesaing }\end{array}$ \\
\hline SI Perekrutan & $\begin{array}{l}\text { 1. Analisis rekrutment } \\
\text { 2. Informasi tenaga kerja } \\
\text { 3. Jadwal wawancara }\end{array}$ \\
\hline SI Tunjangan & $\begin{array}{l}\text { Informasi Penggajian: Absen masuk, } \\
\text { jam kerja, Gaji pokok \& Bonus }\end{array}$ \\
\hline SI Laporan & $\begin{array}{l}\text { Laporan tentang keluhan: Kecelakanaan, } \\
\text { kesehatan dan Lingkungan kerja }\end{array}$ \\
\hline $\begin{array}{l}\text { SI Mutasi, Pangkat \& } \\
\text { Teguran }\end{array}$ & $\begin{array}{l}\text { 1. Mengelola data mutasi karyawan. } \\
\text { 2. Mengelola data kenaikan pangkat. } \\
\text { 3. Mengelola data teguran }\end{array}$ \\
\hline
\end{tabular}

Analisis Lingkungan SI/TI Eksternal PT X terdapat proses dilakukan guna mengetahui perkembangan teknologi PT X:

1) Pengembangan teknologi basis website, mendorong PT pemanfaatan teknologi pada kegiatan peningkatan pelayanan.

2) Peluang unggul kompetitif dari pesaing

3) Memanfaatkan teknologi ditiap kegiatan oprasional menetapkan PT X terdepan di Pagar Alam, hingga punya nilai keunggulan berkompetensi yang tinggi

Rencana strategis SI disusun berdasarkan analisa internal dan eksternal lingkungan bisnis serta analisa internal dan eksternal lingkungan SI/TI kampus PT X. Dari hasil analisa didapatkan rencana strategis SI ke depan membantu menentukan portfolio aplikasi SI harus dibangun. Penentuan strategi diawali penentuan strategi bisnis SI, kemudian penentuan strategi manajemen SI/TI dan strategi SI PT X.

\section{B. Analisis Value Chain.}

Hasil analisis value chain PT X untuk pembagian aktifitas masing-masing unit:

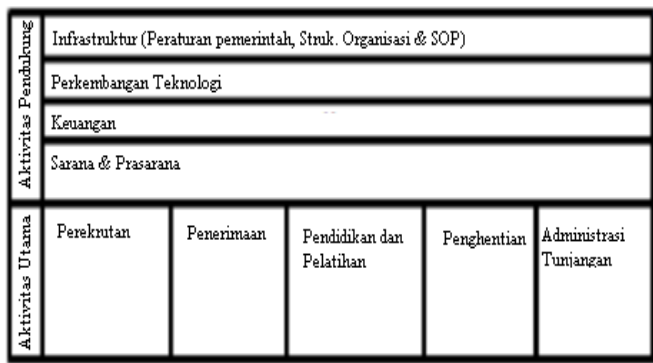

Gambar 5. Analisis Value Chain

\section{Analisis five force porter.}

Analisis Five Forces Model digunakan menentukan posisi PT X terhadap lingkungan eksternal yang mempengaruhi jalannya proses bisnis PT X. Berikut ini adalah hasil analisis Five Forces. 


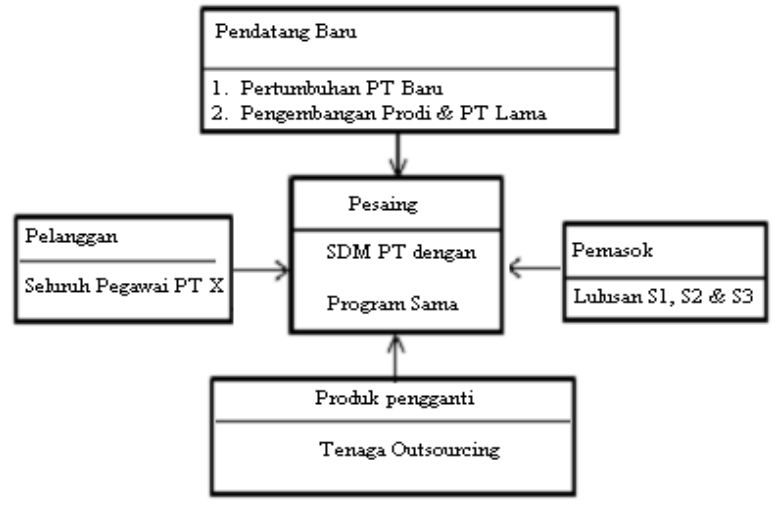

Gambar 6 Analisis Five Forces

\section{Implementasi dan hasil}

Hasil analisis Value chain dan Five Forces poerter Model maka didapat target aplikasi beberapa SI Data SDM, SI Penelitian SDM, SI Intelijen SDM, SI Perencanaan SDM, SI Perekrutan, SI Tunjangan, SI Pelaporan, SI Mutasi, Kenaikan golongan \& teguran. Berdasarkan identifikasi kebutuhan SI SDM PT X, hasil analisa value chain aktifitas utama dan pendukung, dapat disusun Future Application Portfolio dengan McFarlan's Strategic Grid seperti tampak pada Tabel.

TABEL 2

\begin{tabular}{|c|c|}
\hline \multicolumn{2}{|c|}{ MCFARLAN'S STRATEGIC GRID } \\
\hline Strategic & High Potensial \\
\hline $\begin{array}{l}\text { SI Penelitian } \\
\text { SDM } \\
\text { SI Pelaporan }\end{array}$ & SI Inteligen SDM \\
\hline $\begin{array}{l}\text { SI Data SDM } \\
\text { SI Perencanaan } \\
\text { SI Perekrutan }\end{array}$ & $\begin{array}{l}\text { SI Tunjangan } \\
\text { SI Mutasi, kenaikan pangkat, } \\
\text { teguran }\end{array}$ \\
\hline Key Operation & Support \\
\hline
\end{tabular}

TABEL 3

PRIORITAS APLIKASI MENDATANG

\begin{tabular}{|l|l|l|}
\hline No & \multicolumn{1}{|c|}{ Aplikasi } & Waktu \\
\hline 1 & SI Data sumber daya manusia & 2018 \\
\hline 2 & SI Perekrutan & 2018 \\
\hline 3 & SI Tunjangan & 2018 \\
\hline 4 & $\begin{array}{l}\text { SI Kenaikan pangkat, golongan dan } \\
\text { teguran }\end{array}$ & 2019 \\
\hline 5 & SI Mutasi & 2019 \\
\hline 6 & SI Pelaporan & 2019 \\
\hline 7 & SI Penelitian sumber daya manusia & 2020 \\
\hline 8 & SI Intelijen sumber daya manusia & 2020 \\
\hline 9 & SI Perencanaan sumber daya manusia & 2020 \\
\hline
\end{tabular}

\section{KESIMPULAN}

Melalui metode dan analisis yang di gunakan maka diperoleh kesimpulan dan saran, sebagai berikut:

1) Setelah di analisis, rencana strategis SI SDM PT X bisa ditarik kesimpulan, Analisis rencana strategi SI mendatang dari Hasil analisis internal menggunakan value chain memerlukan beberapa aplikasi SI, Hasil analisis lingkungan eksternal menggunakan analisi Five Force porter menampilkan potensi pesaing SI, membantu kegiatan pengelolan SDM PT. Usulan rencana strategis SI mendatang menggunakan portopolio Mcfarlan.

2) Saran yang dapat digunakan PT $X$ dalam perencanaan strategis SI: Pada saat membuat dokumen rencana SI strategis bisa ditambahkan rencana anggaran tiap SI \& kebutuhan SDM, dan perencanaan SI PT X dapat dibuat blueprint

\section{REFERENS}

[1] ---., 2015., "Rencana Strategis SI/TI Pada STTP"., Tidak terbit Thesis., Fak.Ilkom. Program Pasca Sarjana S2 MTI Universitas Bina Darma., Palembang.

[2] ---.,2015., "Perencanaan strategis sistem informasi PTS Pagar Alam menggunakan pendekatan blue ocean strategi dan balanced scorecard". Jurnal Be-Trik., Vol.05., No. 02., ISSN: 2339-1871., PP. 1-14.

[3] Ramdhany, Tri. dkk. 2013. Perancanaan Strategi Sistem Informasi Retail Studi Kasus : PT. Retail, Jurnal LPKIA.

[4] Retnowati, Dwi. dkk. 2011. Penerapan SI Menggunakan Analisis Value Chain: Studi Kasus PT Intan Pariwara Klaten.

[5] Yosef, Hendrik. 2011. Perencanaan Strategies Sistem Informasi pada Institusi Pendidikan Tinggi Studi Kasus Sekolah Tinggi Ilmu Komunikasi dan Sekretari Tarakanita, Seminar Snati.

[6] Ward, J \& Peppard, J. 2002, Strategic planning for information systems: 3rd edition, John Wiley and Sons.

[7] Jogiyanto, H.M., 2005, Analisa dan Desain Sistem Informasi: Pendekatan Terstruktur Teori dan Praktik Aplikasi Bisnis, ANDI, Yogyakarta.

[8] Hunger, J. David dan Wheelen, Thomas L. 2003. Manajemen Strategis. Andi. Yogyakarta. 